\title{
Breast Feeding Practices among Rural Women in a selected area of Bangladesh
}

\author{
M Rahman' ${ }^{1}$ N Begum², M M Rahman ${ }^{3}$, S K Nayann ${ }^{4}$ S N Zinia ${ }^{5}$
}

1 Dr. Mumtaz Rahman Assistant Professor Dept. of Community Medicine Northern International Medical College

Dr. Nasreen Begum

Assistant Professor

Dept. of Community Medicine

Northern International Medical College

${ }^{3}$ Dr. Md. Mahbubar Rahman

Associate Professor

Dept. of Community Medicine

Northern International Medical College

${ }^{4}$ Dr. Shafia Khatun Nayan

Lecturer

Dept. of Community Medicine

Northern International Medical College

${ }^{5}$ Dr. Sumsun Nahar Zinia

Lecturer

Dept. of Community Medicine

Northern International Medical College

\section{Correspondence}

Dr. Mumtaz Rahman

Assistant Professor

Dept. of Community Medicine

Northern International Medical College

\section{Abstract}

Background : It has been already established that appropriate breast feeding practices reduce child morbidity and mortality; improve immunity in children besides being essential for their optimal growth and development ${ }^{1}$.

Objective : To evaluate the status of breast feeding practices among the women in a selected rural area of Bangladesh.

Methodology : Descriptive, cross-sectional study was conducted between January to June 2013. A total 191 women, age between 18 . $45 y$ rs who had children below 2 years were selected purposively from a village. Mothers were the respondents and data were collected by face to face interview using pretested questionnaire.

Results : Socio demographic characteristics of respondents revealed $80.63 \%$ were house wife; their mean age was 23.91 yrs. Most of them were educated. Economical status was lower middle class. Exclusive breast feeding was found among $70.68 \%$ respondents and $75.92 \%$ mothers fed colostrums to their babies. During antenatal care $84.47 \%$ respondents got advice on breast feeding. Within one hour after birth $56.54 \%$ mothers initiated breast feeding. Total $24.08 \%$ mothers gave pre-lacteal feed. During child's sickness $92.67 \%$ respondents continued breast feeding.

Conclusion : Exclusive Breast feeding practice among rural women which was higher than the national target. Educated mothers were more motivated and also those who received advices on breast feeding during antenatal care. Strengthening of Breast feeding counseling during antenatal care is recommended to maintain sustainability.

Key Words : Exclusive breast feeding (EBF), Prelacteal feeding, Antenatal care.

\section{Introduction}

Breastfeeding is virtually universal (98.3\%) and prolonged in Bangladesh. The mean duration of breastfeeding to be 26.4-28.9 months but the fact is that mothers do not initiate breast feeding early enough with in one hour of birth and do not exclusively breast feed for 6 months. ${ }^{2}$ According to UNICEF, the World's Children Report 2011, 136.7 million babies are born worldwide and only 32.6 per cent of them are breastfed exclusively in the first six months. ${ }^{3}$ Bangladesh Demography \& Health survey (BDHS) reported exclusive breast feeding in Bangladesh is 64\% (2011) and early initiation $43 \%$ ( 2007). ${ }^{4}$

In developing countries about one fourth to one half of all infant deaths occur in the first week of life. Immediate breast feeding within first hour of birth followed by exclusive breast feeding improves the health and survival of new born. Breast feeding provides optimum growth and nutrition, essential for the development of early childhood, composition of existing perfect food and nutrients, contributes to reduce child mortality and improve maternal health. ${ }^{5}$ Initiation of breast feeding within one hour of bith reduces neonatal mortality (32/1000 live birth) by 31 per cent. Breast feeding reduces infants mortality (43/1000 live birth) by 13 per cent within than 5 years, while complementary feeding reduces 6 per cent. ${ }^{3}$

Breastfed children have at least six times greater chance of survival in the early months than nonbreastfed children. ${ }^{4}$ Breast feeding reduces the risk of malnutrition and common infectious diseases in children like pneumonia diarrhea and otitis media, which are the leading causes of infant mortality in developing countries. Pan American Health Organization research shows that breast feeding can also reduce the risk of Type 1 diabetes, childhood leukemia, and atopic dermatitis (a type of skin rash) in babies. Breast feeding has also been shown to lower the risk of SIDS (sudden infant death syndrome). Formula-fed babies also have higher risks of necrotizing enterocolitis, Lower respiratory infections, asthma, obesity, type 2diabetes etc. ${ }^{6}$

Practicing of breast feeding for an infant affected by higher socioeconomic status, higher maternal education and living in the city area. Higher birth order and female sex were associated with increased rates of exclusive breast feeding of infants less than 6 months of age. The beneficial effects of breast feeding depend on the initiation of breast feeding, its duration, and the age at which the breastfed child is weaned. $^{7}$

Antenatal counseling on breast feeding and postnatal lactation support are likely to improve rates of exclusive breast feeding. Awareness related to breast feeding among mothers in the "counseled" group was better than those in the "not counseled" group. ${ }^{8}$ In reality many mothers are unable to practice exclusive breast feeding as advocated. Lack of confidence in mothers' ability to breastfeed, problems with the infant latching or suckling, breast pain or soreness, perceptions of insufficient milk supply, and a lack of individualized encouragement from their clinicians in the early post discharge period are some of the common reasons for early breast feeding discontinuation. $^{9}$ 
Some of these problems can be overcome if the woman is informed antenatally about the benefits of breast feeding and prepared mentally for exclusive breast feeding. A randomized controlled trial conducted in a tertiary hospital in Singapore has revealed that antenatal breast feeding education and postnatal lactation support, as single interventions based in hospital, both significantly improved rates of exclusive breast feeding up to six months after delivery. ${ }^{10}$

The global strategy has identified a clear need for optimal infant feeding practices in reducing malnutrition as well as poverty. It provides guidance on how to protect, promote and support exclusive breast feeding for first six months and continued breast feeding for two years or beyond together with adequate, appropriate and local complementary foods starting from the age of six months. ${ }^{11}$

Materials and methods : This cross-sectional type of descriptive study was carried out between January to June 2013. A total 191 women age between 18- 45yrs who had children below 2 years were selected purposively from village Islampur in Dhamrai upazilla under Dhaka district. Mothers were respondents and after taking informed consent, data were collected by face to face interview, using a pretested questionnaire. Data was entered into SPSS version 16.0 and analyzed by the researchers.

\section{Results}

Table I: Socio-demographic profile of the respondents (no. 191)

\begin{tabular}{|c|c|c|}
\hline Age of respondents(years) & Frequency & Percentage $\%$ \\
\hline $16-20$ & 43 & 22.51 \\
\hline $21-25$ & 83 & 43.46 \\
\hline $26-30$ & 54 & 28.27 \\
\hline $31-35$ & 09 & 4.71 \\
\hline $36-40$ & 02 & 1.05 \\
\hline \multicolumn{3}{|c|}{ Mean age 23.91} \\
\hline \multicolumn{3}{|l|}{ Level of Education } \\
\hline Illiterate & 07 & 3.66 \\
\hline Able to sign only & 19 & 9.95 \\
\hline Primary level & 54 & 28.27 \\
\hline Secondary Level & 69 & 36.13 \\
\hline SSC or Equivalent & 25 & 13.09 \\
\hline HSC or Equivalent \& above & 17 & 8.90 \\
\hline \multicolumn{3}{|l|}{ Occupation } \\
\hline Housewife & 154 & 80.63 \\
\hline Service holder \& others & 37 & 19.37 \\
\hline \multicolumn{3}{|l|}{ Monthly income (Tk) } \\
\hline Below 5,000 & 18 & 9.42 \\
\hline $5,000-10,000$ & 70 & 36.66 \\
\hline $10,001-15,000$ & 43 & 22.52 \\
\hline $15,001-20,000$ & 29 & 15.18 \\
\hline $20,001 \&$ above & 31 & 16.22 \\
\hline \multicolumn{3}{|c|}{ Age of the breastfeed child (months) } \\
\hline $0-4$ & 31 & 16.23 \\
\hline $5-9$ & 37 & 19.37 \\
\hline $10-14$ & 41 & 21.47 \\
\hline $15-19$ & 35 & 18.32 \\
\hline $20-24$ & 47 & 24.61 \\
\hline
\end{tabular}

The study result revealed that $94.24 \%$ respondents were between $16-30$ years of age and mean age 23.91years. It was observed that highest number of mothers $36.13 \%$ was educated up to secondary level next highest were primary level $28.27 \%$. Illiterate and able to sign only were $3.66 \%$ and $9.95 \%$ respectively. It is evident from recent study that economic condition of the respondents was $36.66 \%$ families had monthly income 5,000 - 10,000 Takas, $22.52 \%$ families had 10,000 15,000 TK and $16.22 \%$ families' income was 20,000 TK and above. Regarding age of the breastfed child most of the child (24.61\%) were 20-24 months. (Table I)

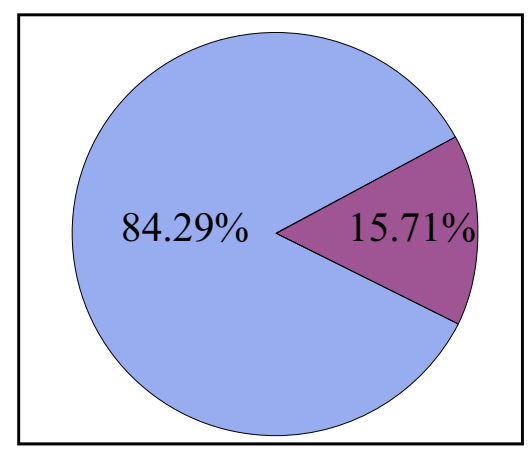

Fig1 Respondents receiving antenatal care

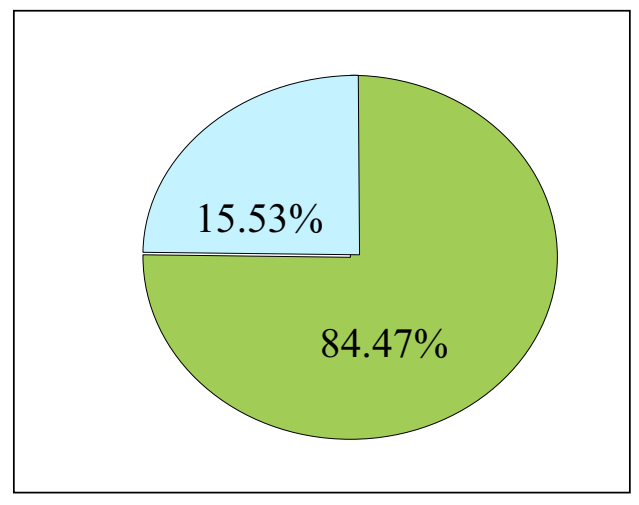

Fig 2 Receiving Breast feeding Advice during ANC

Antenatal care received $84.29 \%$ respondents and $15.71 \%$ did not receive during last pregnancy. Those respondents who received antenatal care $84.47 \%$ got breast feeding advice and $15.53 \%$ did not get breast feeding advice. (Fig1 \& 2) It was evident from current study that exclusive breastfeeding was $70.68 \%$. Time of initiation of breastfeeding $56.54 \%$ were within 1 hour, $14.14 \%$ were within 3 days, after 3 days were $27.75 \%$. Regarding first feeding of the children fed colostrums was given to $75.92 \%$, honey $8.90 \%$ and sugar water and other $15.18 \%$. When mothers $(24.08 \%)$ were asked for not giving colostrums, $65.22 \%$ respondents were unknown about its benefits, children were sick $21.74 \%$ and $6.52 \%$ mothers were sick. (Table II) 
Table II Information regarding Breast feeding practice

Duration of exclusive breast feeding Frequency

$<2$ months

2-4 months

10

23

135

4-6 months

23

Time of initiation of breastfeeding

Within 1 hour

Within 3 days

108

27

56

After 3 days

First feeding during first 3 days of children

Colostrums

145

Honey

Sugar water \& other

17

29

Reason for not giving Colostrums children (no.46)

Benefits unknown

30

Sickness of child

10

6

Sickness of mother

Our study result showed that only $30.89 \%$ respondents had knowledge on expressed breast milk rest 69.11 had no idea about it (Table III). Mothers had breast problem during feeding were cracked nipple $25.72 \%, 11.43 \%$ inverted nipple, breast abscess $5.72 \%$, breast lump 22.88. (Fig 3) It was also evident that $92.67 \%$ mother continued breast feeding during child's sickness (Fig 4)

Table III. Knowledge of the respondents on expressed breast milk

$\begin{array}{lcc}\text { Variable } & \text { Frequency } & \text { Percentage } \\ \text { Yes } & 59 & 30.89 \\ \text { No } & 132 & 69.11 \\ \text { Total } & 191 & 100\end{array}$

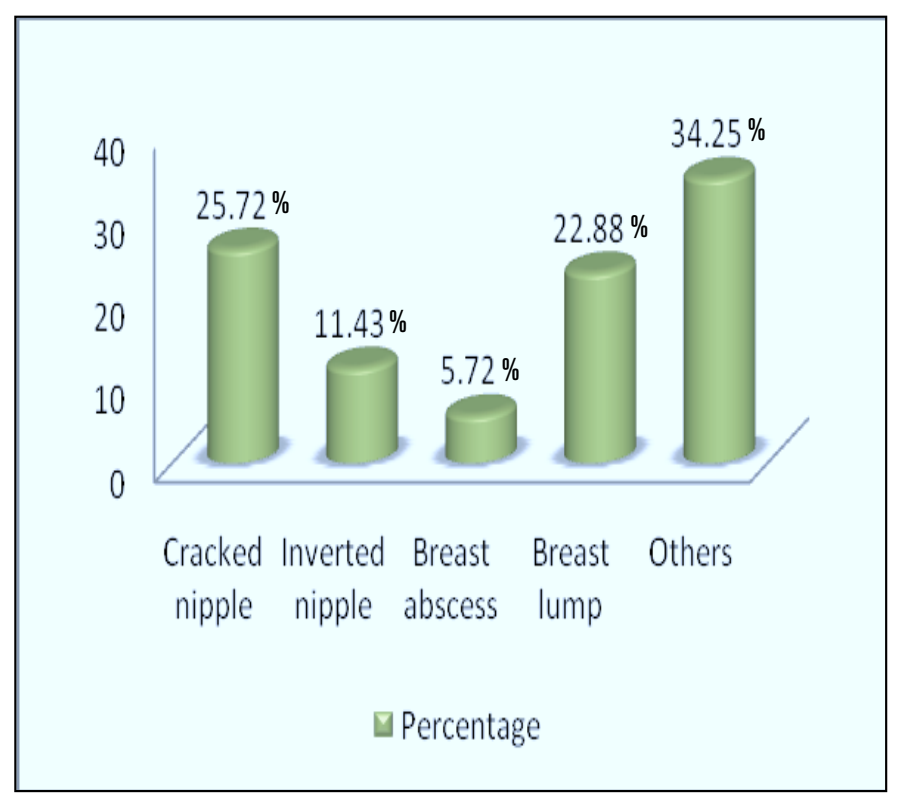

Fig 3 Types of breast problems

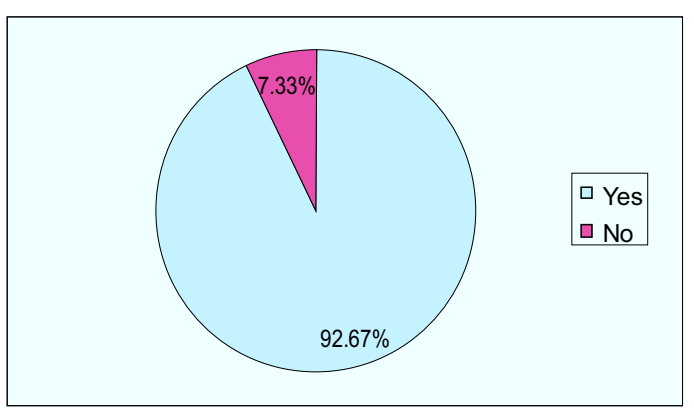

Fig 4 Continuation of breast feeding during child's sickness

\section{Discussion}

The current study on breast feeding practice revealed that nearly half of the respondents (43.46\%) were between age group of $22-25$ yrs. Almost similar result was found in a study done by Community-based peer counselors on exclusive breast feeding practices in Dhaka, Bangladesh that $46 \%$ women were younger (20-26yrs) of all age group included in that study. ${ }^{7}$

Majority of the mother were house wife $(80.64 \%)$ and educated up to primary level $(28.27 \%)$ and secondary level $(36.13 \%)$. M.S Giashuddin et al showed that maximum number of the respondents of were qualified up to secondary level $(30.90 \%)$, primary level $34.50 \%$ and most of the mothers were housewife $(95.5 \%){ }^{9}$

Socio economic status of respondents were poor $36.66 \%$ had the monthly family income 5,000-10,000 taka and $9.42 \%$ had the lowest income as below 5,000 taka. In another study in Bangladesh done by Faruque AS et al revealed similar result that most of the respondents were from lower economic class. ${ }^{12}$ It was found in the current study that $84.29 \%$ mothers received antenatal care among them $84.47 \%$ got breast feeding advice and $15.53 \%$ did not receive antenatal care during last pregnancy. These findings are consistent in some extent in a study in Bangladesh showed that the women who received antenatal care by the health professional had lower risk of terminating breast feeding than the women who did not receive antenatal care. ${ }^{13}$ Study in India with similar age group of child revealed opposite picture that only $21 \%$ had received some antenatal counseling about breast feeding while $79 \%$ had not received any such counseling. ${ }^{14}$

The current study revealed that time of initiation of breastfeeding $56.54 \%$ were within 1 hour, $14.14 \%$ were within 3 days, $27.75 \%$ were after 3 days. The practice of breast feeding among Indian mothers is almost universal, but initiation of breast feeding is quite late and the colostrums is usually discarded. In an Indian study it was found that 295(91\%) mothers gave colostrums and 185 (57\%) initiated breast feeding within one hour of delivery. ${ }^{12}$ It was evident from current study that exclusive breastfeeding was $70.68 \%$. for 6 months, $12.04 \%$ for $2-4$ months, $5.24 \%$ for $<2$ months. Study in Nepal done by Maneswori $U$ et al showed that the prevalence of exclusively breast feeding at 1, 3 and 6 months were $240(74 \%), 78(24 \%)$ and $29(9 \%)$, and mixed feeding was initiated in $49(15 \%), 124(38 \%)$ and 257 (79\%) babies, respectively. ${ }^{15}$ The recent study showed that sugar water $(15.18 \%)$ was the commonest of prelacteal feeding; honey $(8.90 \%)$ was the next. National Surveillance of IPHN revealed only $7 \%$ of the infants was given breast milk as a first feed. Honey (56\%), mustard oil (31\%) and water with sugar (4\%) were found as the most frequently used pre-lacteal 
liquid. Surprisingly, $9 \%$ of infants did not receive any food within 24 hours of birth. ${ }^{16}$

On asking respondents who did not give colostrums answered that $13.04 \%$ were sick, child was sick $21.74 \%$ and $65.22 \%$ were unaware of the benefits of colostrums. Pikee Saxena et al explained similar reasons of discarding colostrums in her study ${ }^{17}$. Our study result showed that only $30.89 \%$ respondents had knowledge on expressed breast milk rest and $69.11 \%$ had no idea about it. Reverse result was found by Nwet $\mathrm{N}$ Win et al that $76.4 \%$ mothers had knowledge on expressed breast milk ${ }^{18}$. Mothers had breast problem during feeding were cracked nipple $25.72 \%$, inverted nipple $11.43 \%$, breast abscess $5.72 \%$ and breast lump $22.88 \%$. These results were consistent with the study done by Ashmika Motee demonstrating that many women experienced similar breast problems during feeding her child ${ }^{19}$. It was also evident that $92.67 \%$ mother continues breast feeding during child's sickness. This indicated that rural women were aware in continuation of breast feeding during her child's sickness.

\section{Conclusion and recommendation}

Breast feeding practice among rural mother was satisfactory. Practice of breastfeeding is higher in the study area than the national data. More intensive interventions are necessary targeting the groups with supoptimal practices, while programmes that cover entire populations are being continued.

\section{References}

1. World Health Organization: Promoting proper feeding for infants and children. http://www.who.int/nutrition/topics/infantfeeding/en/index.html

2. S. Akter and M. M. Rahman, "Duration of breastfeeding and its correlates in Bangladesh," Journal of Health, Population and Nutrition, vol. 28, no. 6, pp. 595-601, 2010.

3. Hafsa M Hanif; Trends in breastfeeding and complementary feeding practices in Pakistan,1990-2007International Breastfeeding Journal 2011, 6:15 doi:10.1186/1746-4358-6-15.

4. Bangladesh Demographic \& Health Survey, 2011. National Institute of Population Research and Training Dhaka, Bangladesh Mitra and Associates Dhaka, Bangladesh

5. Lande B, Andersen LF, Baerug A, Trygg KU, Lund-Larsen K, Veierod MB, Bjorneboe GEA: Infant feeding practices and associated factors in the first six months of life: The Norwegian Infant Nutrition Survey.

6. Leon-Cava N, Lutter C, Ross J, Martin L. Quantifying the benefits of breastfeeding: a summary of the evidence. Washington: Pan American Health Organization, 2002:5-45.

7. Arifeen $S E$, Black RE, Antelman G, Baqui AH, Caulfield L, Becker S. Exclusive breastfeeding reduces acute respiratory infection and diarrhoea deaths among infants in Dhaka slums. Pediatrics 2001;108:67-74.

8. Antenatal counseling on breastfeeding - is it adequate? A Gunasekaran Dhandapany, Adhisivam Bethou*, Arulkumaran Arunagirinathan and Shanthi Ananthakrishnan; descriptive study from Pondicherry, India,International Breastfeeding Journal 2008, 3:5 doi:10.1186/1746-4358-3

9. M.S. Giashuddin \& M. Kabir: Duration of breast-feeding in Bangladesh Indian J Med Res 119, June 2004, pp 267-272

10. Gunasekaran Dhandapany, Adhisivam Bethou, Arulkumaran Arunagirinathan and Shanthi Ananthakrishnan; Antenatal counseling on breastfeeding, is it adequate? A descriptive study from Pondicherry, India International Breastfeeding Journal .2008, 3:5 doi:10.1186/1746-4358-3-5.
11. World Health Organization: Infant and Young Child Feeding. Model Chapter for textbooks for medical students and allied health professionals. France: WHO; 2009.

12. Faruque AS, Ahmed AM, Ahmed T, Islam MM, Hossain MI, Roy SK, Alam N, Kabir I, Sack DA; Nutrition: basis for healthy children and mothers in Bangladesh: J Health Popul Nutr. 2008 September; 26(3): 325-339. PMCID: PMC2740711.

13. Haider R, Ashworth A, Kabir I, Huttly SR: Effect of community-based peer counsellors on exclusive breastfeeding practices in Dhaka, Bangladesh: a randomised controlled trial. Lancet 200, 356(9242):1643-1647.

14. Syed E Mahmood, Anurag Srivastava, P Shrotriya, Payal Mishra; Infant feeding practices in the rural population of north India: Journal of Family \& Community Medicine. Year: 2012 Volume:19 Issue:2 Page:130-135. PMID: 22870418.

15. Manjeswori Ulak, Ram K Chandyo, Lotta Mellander, Prakash S Shrestha and Tor A Strand; Infant feeding practices in Nepal: International Breastfeeding Journal 2012, 7:1 doi:10.1186/1746-4358-7-1.

16. Complementary feeding in rural Bangladesh: family food for breast-fed infants July, 2001 Nutritional Surveillance Project Bulletin No. 6 NUTRITIONAL SURVEILLANCE PROJECTN SP IPHN.

17. Pikee Saxena et al. Contemporary breast feeding practices-A hospital based study; Indian J. Prev. Soc. Med July - Dec, 2006 Vol. 37 No.3\& 4, (170 -176)

18. Nwet N Win, Colin W Binns, Yun Zhao, Jane A Scott, Wendy H Oddy; Breastfeeding duration in mothers who express breast milk: a cohort study, International Breastfeeding Journal 2006, 1:28 doi:10.1186/1746-4358-1-28 ; http://www.internationalbreast feedingjournal.com/content/1/1/28

19. Ashmika Motee, Deerajen Ramasawmy, Prity Pugo-Gunsam, and Rajesh Jeewon; An Assessment of the Breastfeeding Practices and Infant Feeding Pattern among Mothers in Mauritius, Journal of Nutrition and Metabolism Volume 2013 (2013), Article ID 243852, 8 pages http://dx.doi.org/ 10.1155/2013/243852 